\title{
Prevalence of basal ganglia and carotid artery calcifications in patients with permanent hypoparathyroidism after total thyroidectomy
}

\author{
Leyre Lorente-Poch ${ }^{1,2}$, Sílvia Rifà-Terricabras ${ }^{2}$, Juan José Sancho ${ }^{1,2}$, Danilo Torselli-Valladares ${ }^{1}$, Sofia González-Ortiz ${ }^{3}$ \\ and Antonio Sitges-Serra ${ }^{1,2}$
}

${ }^{1}$ Endocrine Surgery Unit, Hospital del Mar, Barcelona, Spain

${ }^{2}$ Departament de Cirurgia, Universitat Autònoma de Barcelona, Barcelona, Spain

${ }^{3}$ Department of Radiology, Hospital del Mar, Barcelona, Spain

Correspondence should be addressed to L Lorente-Poch: Iorentepoch@live.com

\begin{abstract}
Objective: Permanent hypoparathyroidism is an uncommon disease resulting most frequently from neck surgery. It has been associated with visceral calcifications but few studies have specifically this in patients with post-surgical hypoparathyroidism. The aim of the present study was to assess the prevalence of basal ganglia and carotid artery calcifications in patients with long-term post-thyroidectomy hypoparathyroidism compared with a control population.

Design: Case-control study.

Methods: A cross-sectional review comparing 29 consecutive patients with permanent postoperative hypoparathyroidism followed-up in a tertiary reference unit for Endocrine Surgery with a contemporary control group of 501 patients who had an emergency brain CT scan. Clinical variables and prevalence of basal ganglia and carotid artery calcifications were recorded.

Results: From a cohort of 46 patients diagnosed with permanent hypoparathyroidism, 29 were included in the study. The mean duration of disease was $9.2 \pm 7$ years. Age, diabetes, hypertension, smoking and dyslipidemia were similarly distributed in case and control groups. The prevalence of carotid artery and basal ganglia calcifications was 4 and 20 times more frequent in patients with permanent hypoparathyroidism, respectively. After propensity score matching of the 28 the female patients, 68 controls were matched for age and presence of cardiovascular factors. Cases showed a fourfold prevalence of basal ganglia calcifications, whereas that of carotid calcifications was similar between cases and controls.

Conclusion: A high prevalence of basal ganglia calcifications was observed in patients with post-surgical permanent hypoparathyroidism. It remains unclear whether carotid artery calcification may also be increased.
\end{abstract}

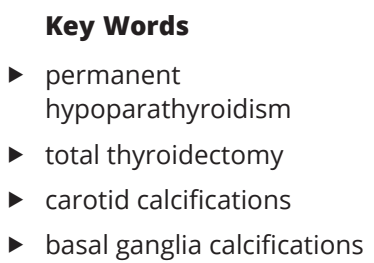

Endocrine Connections (2020) 9, 955-962

\section{Introduction}

Permanent hypoparathyroidism is a rare disorder characterized by low or inappropriately normal levels of parathyroid hormone leading to low calcium and increased phosphate serum levels (1).
Immune-mediated destruction of the parathyroid glands, idiopathic and inherited hypoparathyroidism such as DiGeorge syndrome and activating mutations in the extracellular calcium-sensing receptor or mutations in https://ec.bioscientifica.com https://doi.org/10.1530/EC-20-0387 (c) 2020 The authors Published by Bioscientifica Ltd

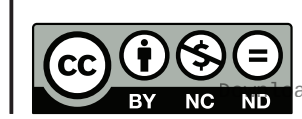

This work is licensed under a Creative Commons Attribution-NonCommercial-NoDerivatives 4.0 Internationab bicense.ifica .com at 04/26/2023 12:55:06PM 
the pre-proPTH, are uncommon causes of permanent hypoparathyroidism (1).

The commonest etiology of permanent parathyroid failure (up to three quarters of the cases $(2,3)$ ) is postoperative hypoparathyroidism mostly due to intraoperative injury to the parathyroid glands, autotransplantation or inadvertent parathyroidectomy (4), all leading to a reduction of the functional parathyroid parenchyma.

As total thyroidectomy has been gaining popularity during the last three decades for the management of a variety of thyroid disorders, postoperative parathyroid failure has emerged as the most common early adverse effect of thyroidectomy, eventually progressing to permanent hypoparathyroidism, a complication requiring life-long medical supervision and treatment.

The estimated prevalence of permanent hypoparathyroidism after total thyroidectomy varies between 0 and $3 \%$ as reported in literature reviews (5) and $6-12 \%$ according to more realistic national registries and multicenter studies (6). Some studies dealing with current management policies, quality of life and the risk of complications have been published in recent years and reviewed in the European Guidelines (7).

A Danish case-control study (8) assessing 668 patients with post-surgical hypoparathyroidism showed that they had almost five-fold increase the rate of renal stones in comparison with the normal population. One year later, the same authors reported a significantly increased risk of hospitalization due to infections and depression/bipolar affective disorders (9). The PARADOX study also captured a significant impact of permanent hypoparathyroidism on the quality of life (10). Our group previously reported at least one clinical adverse event was observed in $56.3 \%$ of patients with post-surgical permanent hypoparathyroidism and a slight decrease of the punctuation in the SF-36 questionnaire for the perceived quality of life that was only significant for the emotional role (11).

Another well-known complication of long-term hypoparathyroidism with uncertain clinical significance is basal ganglia calcifications (BGC). Mitchell et al. (2) found the prevalence of BGC was 51.6\%. Even a higher prevalence of $74 \%$ was found by Goswami et al. (12) in 145 patients with idiopathic hypoparathyroidism. These two authors suggested chronic hyperphosphatemia may contribute to basal ganglia calcifications in hypoparathyroidism. Patients with post-surgical hypoparathyroidism were few or not included in these studies. In a recent study analyzing a cohort of 1133 patients suspected of acute ischemic stroke, female gender, hypertension, diabetes, hyperlipidemia, smoking and previous stroke were associated with BGC; a low BMI and older age were identified as the most powerful predicting risk factors (13).

It has been reported that alteration in calcium, phosphate and parathyroid hormone homeostasis is a predisposing factor for vascular calcification and increases the risk of cardiovascular disease in patients with endstage renal disease $(14,15)$. This same relationship in patients with permanent hypoparathyroidism remains unexplored. Underberg et al., showed the cardiovascular risk was increased in non-surgical hypoparathyroidism but not in post-surgical hypoparathyroidism (8). The Rotterdam study (16) found current smoking, age, hypertension, hypercholesterolemia and diabetes were risk factors for calcifications in carotid, coronary and aortic arch branches.

No studies have specifically investigated the occurrence of visceral calcifications in patients with permanent hypoparathyroidism of surgical etiology. Thus, the aim of the present work was to investigate the prevalence of BGC and carotid calcification in patients with post-thyroidectomy hypoparathyroidism compared with that in the general population.

\section{Methods}

A case-control study was designed as a cross-sectional review comparing the prevalence of visceral calcifications. Cases were 46 consecutive patients (Fig. 1) with permanent postoperative hypoparathyroidism whose data was obtained from a single-center prospectively maintained clinical database. These patients had either total thyroidectomy (with or without lymph node dissection) or either for benign or malignant condition or thyroparathyroidectomy for concomitant primary hyperparathyroidism between 1984 and 2017. Patients with secondary hyperparathyroidism were excluded. All the procedures were performed by the same team of experienced endocrine surgeons at the Hospital Universitari del Mar in Barcelona, Spain, a referral center for Endocrine Surgery.

Patients diagnosed with permanent hypoparathyroidism were followed-up in our outpatient clinic every 6 months monitoring intact PTH (iPTH), serum calcium, 25-hydroxyvitamin D, 1,25-dihydroxyvitamin D, and kidney function (creatinine and estimated glomerular
This work is licensed under a Creative Commons Attribution-NonCommercial-NoDerivatives 4.0 elnternational dicense ifica. com at 04/26/2023 12:55:06PM 
Case Serles

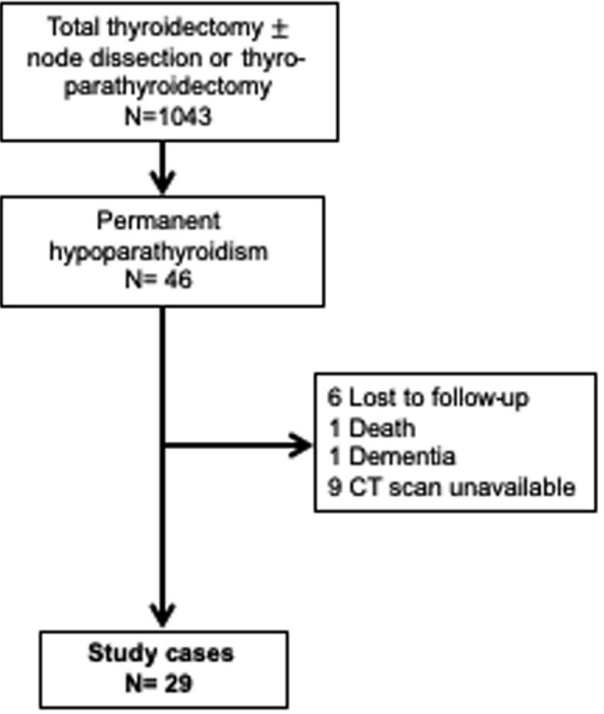

Control Series

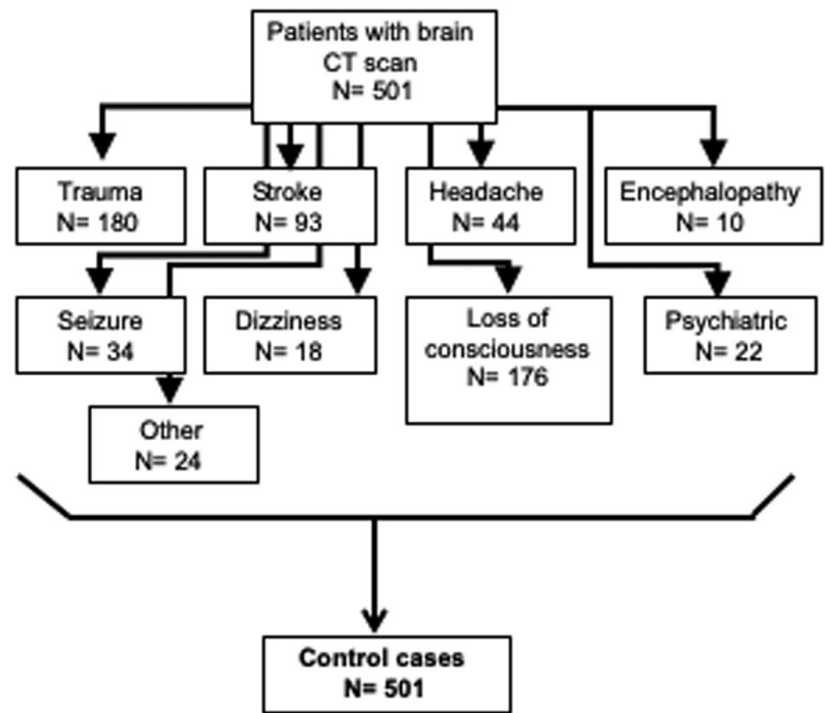

Figure 1

Patient flow diagram.

filtration). Typically, patients received treatment with calcium salts (1.5-3.0 g of calcium/day) and vitamin D analogues: calcitriol (Rocaltrol ${ }^{\circledR}$ ), 0.25-1.00 $\mu \mathrm{g} / \mathrm{day}$ and/or calcifediol (Hidroferol ${ }^{\circledR}$ ), $266 \mathrm{mg}$, one to three times/week. There was no formal criterion to use one or the other (11) but calcifediol was the preferred drug for patients with creatinine $>1 \mathrm{mg} / \mathrm{dL}$.

iPTH levels were determined using either an immuneradiometric second generation assay using IRMA Total Intact assay (Scantibodies Laboratory Inc. Santee, CA, USA) or a solid-phase, two-site chemiluminescent enzyme-labeled assay IMMULITE 2000 Intact PTH assay (Siemens Healthcare Diagnostics Spain, Madrid, Spain); with a normal range of 13-65 pg/mL and a detection limit of $3 \mathrm{pg} / \mathrm{mL}$. In addition to routine kidney ultrasound, bone mineral density scan (DXA), 24-h urine calcium test, some patients agreed to undergo CT-scan to assess BGC and carotid calcifications.

The control group consisted of patients $(n=501)$ who attended the Emergency Department for either head trauma, stroke or headache and had a cranial CT-scan between January and April 2018 (Fig. 1). Information on smoking, blood pressure and lipid-lowering medication use was obtained through the medical records and electronic prescription system.

The study was approved by Hospital del Mar Ethics Committee. Written informed consent was obtained from all the cases.

\section{Sample size}

The case-cohort consisted of 46 patients with permanent hypoparathyroidism diagnosed and followed at a single center. The relatively small sample size for this study reflects the low-rate of this complication in a specialized unit (about $4.5 \%$ of all total thyroidectomies).

The estimated prevalence of basal ganglia calcification in the general population lies somewhere between 2 and $12.5 \%(17,18)$. Large population studies have reflected a prevalence of carotid calcifications ranging between 2 and $4 \%(19,20)$. To obtain a minimum number of BGC and carotid calcifications, a control sample of 500 patients was selected.

Prevalence of basal ganglia and carotid artery calcifications was assessed with CT scan and supra-aortic ultrasound when available.

\section{Definitions}

Permanent hypoparathyroidism was defined as a subnormal iPTH concentration $(<13 \mathrm{pg} / \mathrm{mL})$ and need for calcium replacement with or without activated vitamin D metabolites for more than 1 year after surgery $(6,21)$. A few patients recovering after this time period were not included (22).

Regarding cardiovascular risk factors, the subjects were categorized as current, past and non-smokers. We defined hypertension, hypercholesterolemia and diabetes as the

his work is licensed under a Creative Commons Attribution-NonCommercial-NoDerivatives 4.0 Internationab License ifica com at $04 / 26 / 2023$ 12:55:06PM 
use of blood pressure-lowering medication, lipid reducing medication or of anti-diabetic drugs, respectively. Height and weight were measured in cases, and the BMI was calculated (weight $(\mathrm{kg}) /$ height $\left.(\mathrm{m})^{2}\right)$. We defined obesity as a $\mathrm{BMI}>30 \mathrm{~kg} / \mathrm{m}^{2}$.

Carotid calcifications were defined as calcifications reported by radiologists in the brain CT scan and/or described in a supra-aortic Doppler ultrasound. BGC was defined according to findings on the brain CT-scan reviewed by a Neuroradiologist.

\section{Statistical analysis}

Comparison of proportions was investigated with the Chi-square or exact Fisher tests as appropriate. The Kolmogorov-Smirnov test was used to assess the normal distribution of quantitative variables. Quantitative and normally distributed variables were compared using unpaired Student's $t$-test and values were expressed as mean \pm S.D.

Statistical significance was set at $P<0.05$. Stepwise forward binomial logistic regression analysis was used to isolate the independent predicting factors for supraaortic and basal ganglia calcifications. Propensity Score Matching was used to select a minimum of two controls for case. Statistical analyses were carried out using SPSS IBM Statistics v.22.0.

\section{Results}

From a total of 46 patients diagnosed with permanent hypoparathyroidism, 29 agreed to be included in the study and underwent a brain CT scan (Fig. 1). All but one were females (23). Mean age was $62 \pm 17$ years. Thyroidectomy had been performed for benign goiter in $20(69 \%)$ patients and for thyroid cancer in 9 (31\%) patients. The mean length of follow-up was $9.2 \pm 7$ years.

Control brain CT scans were obtained from 501 patients who attended the emergency department for a variety of reasons (Fig. 1). Around half of the controls were male patients with a mean age of $66 \pm 21$ years.

Age and risk factors for BGC and carotid calcifications such as diabetes, hypertension, smoking and dyslipidemia were similarly distributed in both groups. Male gender was less common among the cases. Overall visceral calcifications (including both, carotid and BGC), were almost seven times more prevalent in the case group. The prevalence of carotid calcification was four-fold in the case group. BGC was located mainly in globus pallidus and tended to be bilateral in both, cases and controls (Table 1). Figures 2, 3 and 4 show CT scan imagine of basal ganglia and vascular calcifications. Patients with permanent hypoparathyroidism had a 20 times higher prevalence of BGC (Table 2).

After propensity score matching of the 28 the female patients, 68 controls were matched for age and presence of cardiovascular factors (Table 3). Cases showed almost a four-fold prevalence of BGC, whereas that of carotid calcifications was similar between female cases and controls.

In multivariate analysis of both cohorts (530 patients), gender, age, permanent hypoparathyroidism, smoking, hypertension, dyslipidemia and diabetes were coded as dichotomous variables. The binomial logistic regression model (Table 4) isolated permanent

Table 1 Description of basal ganglia calcifications in five controls and six cases.

\begin{tabular}{|c|c|}
\hline Patient & Case/control \\
\hline FUF & Control \\
\hline MEWV & Control \\
\hline $\mathrm{ABP}$ & Control \\
\hline JME & Control \\
\hline EAC & Control \\
\hline
\end{tabular}

\begin{tabular}{c} 
Gender \\
\hline M \\
F \\
F \\
F \\
F
\end{tabular}

\begin{tabular}{c} 
Age \\
\hline 53 \\
77 \\
80 \\
80 \\
51
\end{tabular}

\begin{tabular}{l} 
Location \\
\hline Globus pallidus \\
Globus pallidus \\
Globus pallidus \\
Globus pallidus \\
Globus pallidus \\
Lenticular nucleus \\
Thalamus \\
Caudate nucleus \\
Globus pallidus \\
Globus pallidus \\
Globus pallidus \\
Globus pallidus \\
Globus pallidus \\
Globus pallidus
\end{tabular}

\begin{tabular}{l}
\hline Side \\
\hline Bilateral \\
Bilateral \\
Bilateral \\
Bilateral \\
Bilateral \\
\\
Left \\
Right \\
Right \\
Bilateral \\
Left \\
Bilateral
\end{tabular}

\begin{tabular}{l}
\hline Measurements $(\mathrm{mm})(\mathrm{AP} / \mathrm{LL} / \mathrm{CC})$ \\
\hline $7 * 7 * 8$ (right) $6 * 2 * 3$ (left) \\
$3 * 1 * 4$ (right) $5 * 1 * 5$ (left) \\
$7 * 4 * 8$ (right) $8 * 6 * 7$ (left) \\
$10 * 5 * 10$ (right) $14 * 5 * 9$ (left) \\
$8 * 5 * 8$ (right) $11 * 4 * 8$ (left) \\
$10 * 2 * 5$ (right) $6 * 2 * 3$ (left) \\
$8 * 7 * 8$ (right) $9 * 6 * 9$ (left) \\
$18 * 6 * 16$ (right) $11 * 6 * 13$ (left) \\
$1 * 1 * 8 x$ \\
$1 * 1 * 3$ \\
$1 * 1 * 4$ \\
$9 * 6 * 7$ (right) $8 * 4 * 8$ (left) \\
$2 * 1 * 7$ \\
$7 * 3 * 8$ (right) $8 * 5 * 9$ (left)
\end{tabular}

$\mathrm{AP}$, anteroposterior; CC, caudocranial; LL, latero-lateral.

https://ec.bioscientifica.com https://doi.org/10.1530/EC-20-0387 (c) 2020 The authors Published by Bioscientifica Ltd

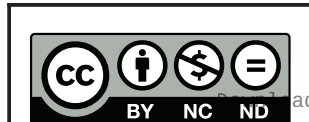

This work is licensed under a Creative Commons Attribution-NonCommercial-NoDerivatives 4.0 Internationad ticense.ifica.com at 04/26/2023 12:55:06PM 


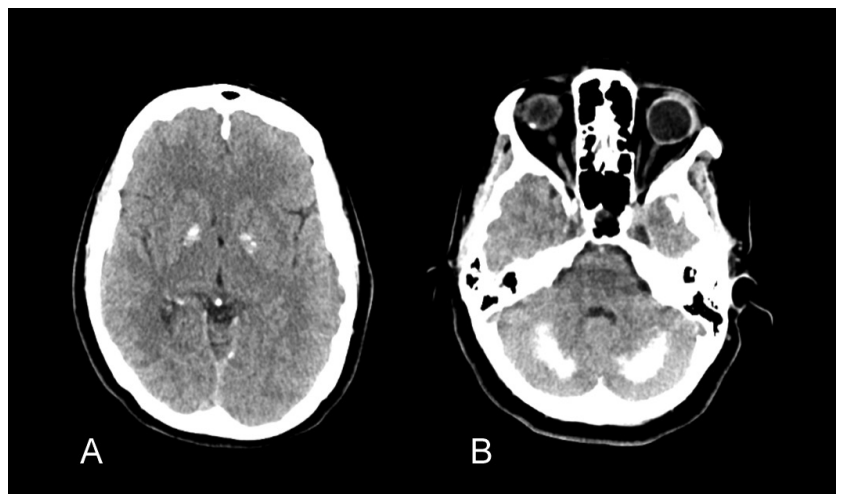

Figure 2

CT scan imaging of a hypoparathyroid 68-year-old female patient with bilateral globus pallidus (A) and dentate nuclei of cerebellum (B) calcifications.

hypoparathyroidism, diabetes and dyslipidemia as independent predictors of overall visceral and carotid calcifications; for the latter, hypertension and smoking were also predictive factors. Only hypoparathyroidism and to a lesser extent, smoking habit were independent factors for BGC.

An independent analysis was performed to compare those patients with permanent hypoparathyroidism who developed $(n=10)$ or did not develop $(n=19)$ calcifications (3 of them had both carotid and BG calcifications). No association could be identified between and the absence vs presence of BGC and BMI (29.9 vs $\left.28.6 \mathrm{~kg} / \mathrm{m}^{2}, P=0.633\right)$, age (50.3 vs 57.4 years, $P=0.372$ ), duration of disease (10 vs 12 years, $P=0.441)$ or phosphate $(4.32 \mathrm{vs} 4.24 \mathrm{mg} / \mathrm{dL}$, $P=0.841)$ and creatinine serum levels $(0.78 \mathrm{vs} 1.13 \mathrm{mg} / \mathrm{dL}$, $P=0.351)$. Whether PTH was undetectable (4.3\% vs $20 \%$ ) or low but detectable ( $95.7 \%$ vs $80 \%)$, did not have an impact on the prevalence of BGC $(P=0.362)$, probably due

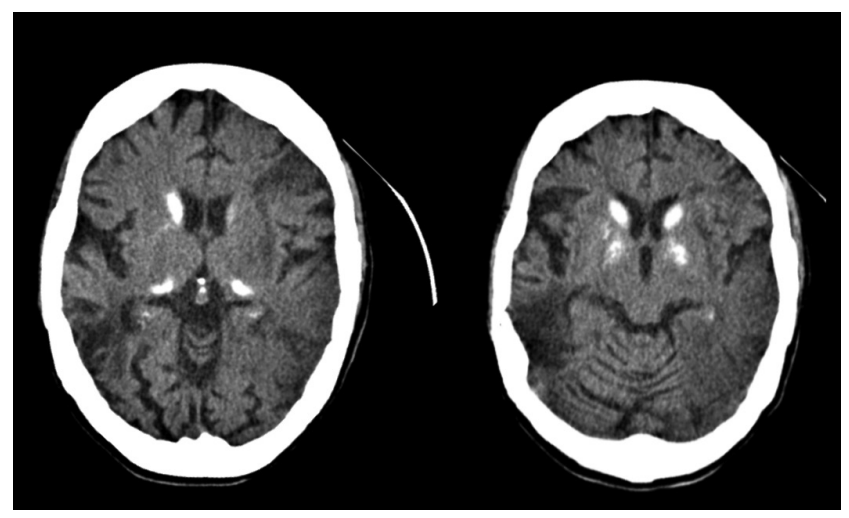

Figure 3

CT scan imaging of a 51-year-old female control with bilateral calcifications of globus pallidus, lenticular nucleus, thalamus and caudate nucleus. to small sample size. Episodes of hypercalcemia $(35.3 \%$ vs $40 \%, P=1$ ) or hypocalcemia (38.9\% vs $10 \%, P=0.194$ ) did not correlate with BGC. Additionally, there was no relation with the type of active vitamin $\mathrm{D}$ drugs they were receiving (calcitriol (35\% vs 40\%); and calcifediol (65\% vs 60\%), $P=1$ ). Patients with BGC was receiving significantly higher doses of daily calcium (2.6 vs $1.4 \mathrm{~g}$, $P=0.030)$. All patients with $\mathrm{BGC}$ was receiving vitamin $\mathrm{D}$ analogues, whereas only $56.3 \%$ of patients without BGC did $(P=0.123)$.

\section{Discussion}

Few authors have investigated the long-term clinical implications of hypoparathyroidism and even fewer have assessed the prevalence of visceral calcifications. To our knowledge, the present study is the only one comparing the prevalence of BGC between patients with postoperative permanent hypoparathyroidism and the general population and specifically assessing carotid calcifications. The close patient monitoring carried out at our Unit differs from the previous publications $(2,8,9)$, whose data were mostly collected from national registries.

Cross-sectional brain imaging was available in 60\% of our post-surgical hypoparathyroid patients showing a prevalence of BGC of $24 \%$. This is lower than the $50-73 \%$ reported by other authors. Etiology and duration of disease may be the main reason. Goswamy et al. assessed patients with idiopathic hypoparathyroidism and in the study done by Mitchell et al. a mix of idiopathic, autoimmune and post-surgical hypoparathyroidism was included and CT scan was only available for $26 \%$ of the cohort. Nevertheless, other previous cohort studies observed basal ganglia calcifications in $12-36 \%(24,25)$. In neither of these studies were patients routinely screened for BGC.

Our analysis revealed that patients with post-surgical hypoparathyroidism had a four-fold risk for BGC when compared with a matched population. Unlike a recent cohort-study of acute ischemic stroke patients (13), female gender, hypertension, diabetes, hyperlipidemia and older age were not associated with BGC.

Some authors have suggested that BGC could be associated with the duration of illness (26). In our cohort, however, there was no correlation between duration of permanent hypoparathyroidism and the development of calcifications.

In the present study, carotid calcifications were five times more prevalent in patients with permanent hypoparathyroidism, than in the control group.

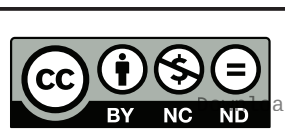

This work is licensed under a Creative Commons Attribution-NonCommercial-NoDerivatives 4.0 elfternationad bicense ifica.com at 04/26/2023 12:55:06PM 


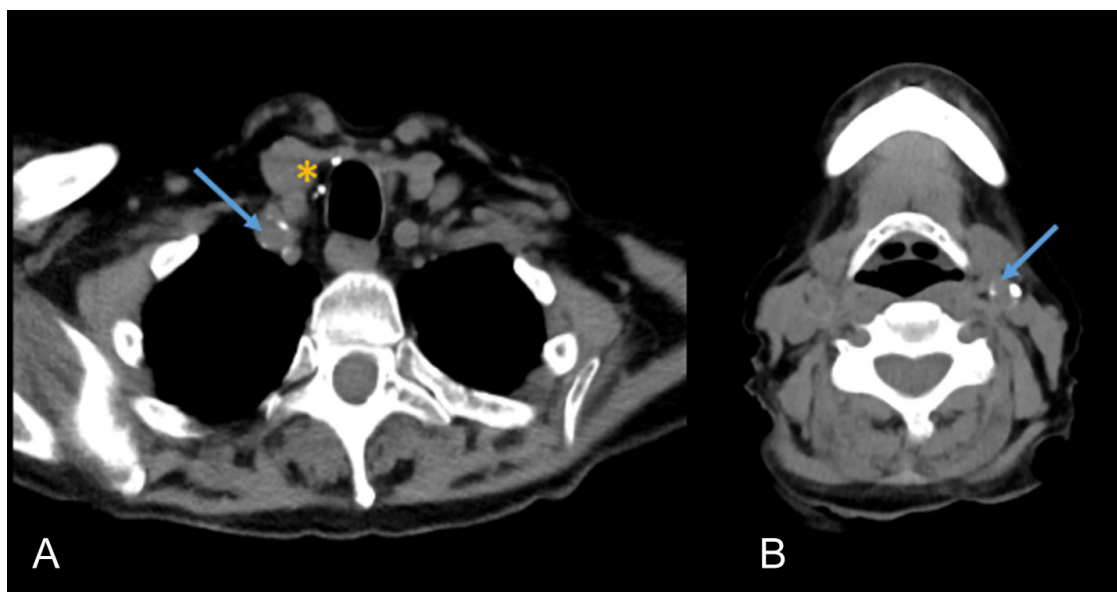

\section{Figure 4}

CT scan imaging of a hypoparathyroid 90 years old female patient with calcification in (A) right subclavia artery (arrow) and surgical clips $\left({ }^{*}\right)$, and (B) left carotid bifurcation (arrow) after

thyroidectomy for benign goiter.

After matching, however, this difference disappeared. The relatively small sample precludes any final conclusion.

The Rotterdam study (16) assessed vascular calcifications in 1003 patients and found that hypertension, hypercholesterolemia and diabetes were significant or near significant risk factors for carotid, aortic arch and coronary calcifications and age and current smoking were the strongest independent risk factors. In the multivariate-adjusted model, current smoking was associated with carotid calcification both in women and in men. All these risk factors were similar between cases and controls in our study. Consistently, binomial logistic regression isolated diabetes, dyslipidemia, hypertension and current smoking as predictors for carotid calcifications, being permanent hypoparathyroidism the most powerful

Table 2 Demographic variables, cardiovascular risk factors and prevalence of basal ganglia and carotid calcifications of 29 patients with postoperative permanent hypoparathyroidism (cases) and 501 controls.

\begin{tabular}{|c|c|c|c|}
\hline & Cases $(n=29)$ & Controls $(n=501)$ & $P$ \\
\hline Age (years) ${ }^{a}$ & $62 \pm 17(26-95)$ & $66 \pm 21(4-100)$ & 0.352 \\
\hline Gender & & & $<0.001^{b}$ \\
\hline Male & $1(3.4)$ & $264(52.7)$ & \\
\hline Female & $28(96.6)$ & $237(47.3)$ & \\
\hline Diabetes & $5(17.2)$ & $129(25.7)$ & 0.383 \\
\hline Hypertension & $13(44.8)$ & $276(55.1)$ & 0.281 \\
\hline Dyslipidaemia & $11(37.9)$ & 165 (32.9) & 0.579 \\
\hline Smoker status & & & 0.695 \\
\hline Non-smoker & $22(75.9)$ & $411(82)$ & \\
\hline Smoker & 4 (13.8) & $54(10.8)$ & \\
\hline Ex-smoker & $3(10.3)$ & $36(7.2)$ & \\
\hline $\begin{array}{l}\text { Carotid } \\
\text { calcifications }\end{array}$ & $7(24.1)$ & $26(5.2)$ & $<0.001$ \\
\hline BG calcifications & $6(20.7)$ & $5(1)$ & $<0.001$ \\
\hline
\end{tabular}

predictor. On the contrary, age was not associated with carotid calcifications.

A case-control study from India assessing thirty patients with sporadic idiopathic hypoparathyroidism found thicker ultrasound measured intima-media in carotid, aortic and renal arteries when compared with healthy subjects. In these patients, serum calcium, iPTH levels were low, whereas serum phosphate levels significantly higher. No significant correlation was observed, however, between biochemical and intima-media thickness or other cardiovascular risk factors (27). The authors concluded that vascular risk was increased in patients with sporadic idiopathic hypoparathyroidism (28).

Carotid artery calcifications, particularly those close to carotid bifurcation, may result in important vascular obstruction causing stroke. Calcified atheroma plaques in carotid arteries may represent an independent marker for ischemic symptoms $(29,30,31)$.

Underberg et al. analyzed the occurrence of ischemic heart disease, stroke and heart failure and concluded that

Table 3 Prevalence of basal ganglia and carotid calcifications in female patients after propensity score matching by age, presence of diabetes, hypertension, dyslipidemia and smoke status to mate cases-controls.

\begin{tabular}{|c|c|c|c|}
\hline & Cases $(n=28)$ & Controls $(n=68)$ & $\boldsymbol{P}$ \\
\hline Age (years) & $62.3 \pm 17$ & $63.5 \pm 21$ & 0.739 \\
\hline Diabetes & $4(14.3)$ & $23(33.8)$ & $0.079^{a}$ \\
\hline Hypertension & $12(42.8)$ & $33(48.5)$ & 0.613 \\
\hline Dyslipidaemia & $10(35.7)$ & $28(41.2)$ & 0.619 \\
\hline Smoker & $3(10.7)$ & $5(7.4)$ & $0.892^{a}$ \\
\hline Carotid calcifications & $6(21.4)$ & $9(13.2)$ & 0.315 \\
\hline BG calcifications & $6(21.4)$ & $4(5.9)$ & $0.031^{\mathrm{a}}$ \\
\hline
\end{tabular}

Values in parentheses are percentages. Quantitative values are expressed in mean \pm S.D.

aFisher's exact test.

BG, basal ganglia. 
Table 4 Binomial Logistic Regression analysis of independent predictors for carotid and basal ganglia calcifications in the 29 cases and 501 controls.

\begin{tabular}{|c|c|c|c|c|c|c|c|}
\hline \multirow[b]{2}{*}{ Risk factor } & \multirow[b]{2}{*}{ Regression coefficient } & \multirow[b]{2}{*}{ S.E. } & \multirow[b]{2}{*}{ Wald } & \multirow[b]{2}{*}{$P$ value } & \multirow[b]{2}{*}{ OR } & \multicolumn{2}{|c|}{$95 \% \mathrm{Cl}$} \\
\hline & & & & & & Lower & Upper \\
\hline \multicolumn{8}{|c|}{ Carotid calcifications } \\
\hline PHP & 2.347 & 0.602 & 15.209 & $<0.001$ & 10.459 & 3.21 & 34.03 \\
\hline Diabetes & 1.357 & 0.439 & 9.555 & 0.002 & 3.885 & 1.64 & 9.19 \\
\hline Dyslipidaemia & 1.147 & 0.446 & 6.620 & 0.010 & 3.149 & 1.31 & 7.55 \\
\hline Hypertension & 1.401 & 0.680 & 4.246 & 0.039 & 4.061 & 1.07 & 15.40 \\
\hline Smoker & -0.935 & 0.519 & 3.247 & 0.072 & 0.393 & 0.14 & 1.08 \\
\hline \multicolumn{8}{|c|}{ Basal ganglia calcifications } \\
\hline PHP & 3.532 & 0.654 & 29.187 & $<0.001$ & 34.19 & 9.49 & 123.12 \\
\hline Smoker & 0.971 & 0.395 & 6.028 & 0.014 & 2.64 & 1.22 & 5.73 \\
\hline
\end{tabular}

Binomial logistic regression parameters: Stepwise forward; F to enter 0.05; F to remove: 0.10; Cut point to classify = 0.5; Predicting variables: gender, hypertension, dyslipidemia, diabetes, smoking status and permanent hypoparathyroidism coded as dichotomous; age coded as continuous. PHP, permanent hypoparathyroidism.

cardiovascular risk was not increased in post-surgical hypoparathyroidism (8). In this study, however, the prevalence of carotid calcifications was not assessed, so their possible association with cardiovascular could not be assessed.

Whereas less than half of the controls were female, more than $96 \%$ of the cases were of female gender, consistent with the usual proportion in thyroid disease requiring surgery. To minimize this confounding factor, a propensity score matching was carried out excluding male patients and selecting at least two similar female controls for every patient matching for age, diabetes, hypertension, dyslipidemia and smoking status. Thus, in female patients, the prevalence of carotid calcifications was similar in cases and controls, whereas the prevalence of BGC was four-fold in patients.

A potential limitation of our study is that controls were not representative of general populations and there may be a selection bias since almost 25\% underwent a CT-scan because a stroke was suspected. And yet, the control group had significantly less prevalence of carotid calcifications. Another limitation was that data of BMI was not available for the control group and it has been shown to be a predictive factor for basal ganglia calcifications. We did analyze, however, the influence of BMI on the prevalence of BGC and carotid calcifications in the cases and could not find an association.

BGC is briefly mentioned in the current European Guidelines on the management of permanent hypoparathyroidism that focus primarily on nephrolithiasis and nephrocalcinosis and just state that 'an increase in brain calcifications has only been documented in non-surgical hypoparathyroidism'. They do not make a specific recommendation on monitoring neither for BGC nor for vascular calcifications (7). Although the clinical implications of $\mathrm{BGC}$ is unclear (and need to be addressed in future studies), the present findings indicate that patients should be probably monitored for this.

In conclusion, our study shows a higher prevalence of BGC and, probably, of carotid calcifications among postsurgical permanent hypoparathyroid patients in comparison with a control population. Further studies should be designed to assess the clinical meaning of these findings that may have an impact on patients's quality of life.

\section{Declaration of interest}

The authors declare that there is no conflict of interest that could be perceived as prejudicing the impartiality of the research reported.

\section{Funding}

This study was supported by an Investigator Initiated Research grant from Shire International $\mathrm{GmbH}$, a member of the Takeda group of companies (IIR-ESP-001471).

\section{References}

1 Shoback D. Clinical practice. Hypoparathyroidism. New England Journal of Medicine 2008359 391-403. (https://doi.org/10.1056/ NEJMcp0803050)

2 Mitchell DM, Regan S, Cooley MR, Lauter KB, Vrla MC, Becker CB, Burnett-Bowie SAM \& Mannstadt M. Long-term follow-up of patients with hypoparathyroidism. Journal of Clinical Endocrinology and Metabolism 201297 4507-4514. (https://doi.org/10.1210/jc.20121808)

3 Bilezikian JP, Khan A, Potts JT, Brandi ML, Clarke BL, Shoback D, Jüppner H, D'Amour P, Fox J, Rejnmark L, et al. Hypoparathyroidism in the adult: epidemiology, diagnosis, pathophysiology, target-organ involvement, treatment, and challenges for future research. Journal of Bone Mineral Research 201126 2317-2337. (https://doi.org/10.1002/ jbmr.483)
(C) 2020 The authors Published by Bioscientifica Ltd
This work is licensed under a Creative Commons Attribution-NonCommercial-NoDerivatives 4.0

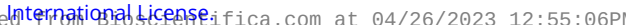


4 Lorente-Poch L, Sancho JJ, Ruiz S \& Sitges-Serra A. Importance of in situ preservation of parathyroid glands during total thyroidectomy. British Journal of Surgery 2015102 359-367. (https://doi.org/10.1002/bjs.9676)

5 Edafe O, Antakia R, Laskar N, Uttley L \& Balasubramanian SP. Systematic review and meta-analysis of predictors of postthyroidectomy hypocalcaemia. British Journal of Surgery 2014101 307-320. (https://doi.org/10.1002/bjs.9384)

6 Lorente-Poch L, Sancho JJ, Muñoz-Nova JL, Sánchez-Velázquez P $\&$ Sitges-Serra A. Defining the syndromes of parathyroid failure after total thyroidectomy. Gland Surgery 20154 82-90. (https://doi. org/10.3978/j.issn.2227-684X.2014.12.04)

7 Bollerslev J, Rejnmark L, Marcocci C, Shoback DM, Sitges-Serra A, Van Biesen W, Dekkers OM \& European Society of Endocrinology. European Society of Endocrinology Clinical Guideline: treatment of chronic hypoparathyroidism in adults. European Journal of Endocrinology 2015 173 G1-G20. (https://doi.org/10.1530/EJE-15-0628)

8 Underbjerg L, Sikjaer T, Mosekilde L \& Rejnmark L. Cardiovascular and renal complications to postsurgical hypoparathyroidism: a Danish nationwide controlled historic follow-up study. Journal of Bone and Mineral Research 201328 2277-2285. (https://doi. org/10.1002/jbmr.1979)

9 Underbjerg L, Sikjaer T, Mosekilde L \& Rejnmark L. Post-surgical hypoparathyroidism - risk of fractures, psychiatric diseases, cancer, cataract, and infections. Journal of Bone and Mineral Research 201429 2504-2510. (https://doi.org/10.1002/jbmr.2273)

10 Hadker N, Egan J, Sanders J, Lagast H \& Clarke BL. Understanding the burden of illness associated with hypoparathyroidism reported among patients in the paradox study. Endocrine Practice 201420 671-679. (https://doi.org/10.4158/EP13328.OR)

11 Lorente-Poch L, Sancho JJ, Carballo L \& Sitges-Serra A. Clinical profile and long-term follow-up of 32 patients with postoperative permanent hypoparathyroidism. Gland Surgery 20176 S3-S10. (https://doi.org/10.21037/gs.2017.11.10)

12 Goswami R, Sharma R, Sreenivas V, Gupta N, Ganapathy A \& Das S. Prevalence and progression of basal ganglia calcification and its pathogenic mechanism in patients with idiopathic hypoparathyroidism. Clinical Endocrinology 201277 200-206. (https://doi.org/10.1111/j.1365-2265.2012.04353.x)

13 Brouwer EJM De, Kockelkoren R, Vis JB De, Dankbaar JW, Velthuis BK, Takx RAP, De Jonghe A, Emmelot-Vonk MH, Koek HL, De Jong PA, et al. Dutch acute stroke study investigators. Prevalence and vascular risk factors of basal ganglia calcifications in patients at risk for cerebrovascular disease. Journal of Neuroradiology 202047 337-342. (https://doi.org/10.1016/j.neurad.2019.04.002)

14 Tentori F, Blayney MJ, Albert JM, Gillespie BW, Kerr PG, Bommer J, Young EW, Akizawa T, Akiba T, Pisoni RL, et al. Mortality risk for dialysis patients with different levels of serum calcium, phosphorus, and PTH: the dialysis outcomes and practice patterns study (DOPPS) American Journal of Kidney Diseases 200852 519-530. (https://doi. org/10.1053/j.ajkd.2008.03.020)

15 Shanahan CM, Crouthamel MH, Kapustin A \& Giachelli CM. Arterial calcification in chronic kidney disease: key roles for calcium and phosphate. Circulation Research 2011109 697-711. (https://doi. org/10.1161/CIRCRESAHA.110.234914)

16 Odink AE, Lugt A Van Der, Hofman A, Hunink MGM, Breteler MMB, Krestin GP \& Witteman JC. Risk factors for coronary, aortic arch and carotid calcification; the Rotterdam Study. Journal of Human Hypertension 201024 86-92. (https://doi.org/10.1038/jhh.2009.42)

17 Fenelon G, Gray F, Paillard F, Thibierge M, Mahieux F \& Guillani A. A prospective study of patients with CT detected pallidal calcifications. Journal of Neurology, Neurosurgery, and Psychiatry 199356 622-625. (https://doi.org/10.1136/jnnp.56.6.622)

18 Gomille T, Meyer RA, Falkai P, Gaebel W, Konigshausen T \& Christ F. Prevalence and clinical significance of computerized tomography verified idiopathic calcinosis of the basal ganglia. Der Radiologe 2001 41 205-210. (https://doi.org/10.1007/s001170050965)

19 Bayram B, Uckan S, Acikgoz A, Müderrisoğlu H \& Aydinalp A. Digital panoramic radiography: a reliable method to diagnose carotid artery atheromas? Dento Maxillo Facial Radiology 200635 266-270. (https:// doi.org/10.1259/dmfr/50195822)

20 Tamura T, Inui M, Nakase M, Nakamura S, Okumura K \& Tagawa T. Clinicostatistical study of carotid calcification on panoramic radiographs. Oral Diseases 200511 314-317. (https://doi. $\operatorname{org} / 10.1111 / \mathrm{j} .1601-0825.2005 .01125 . x)$

21 Stack BC, Bimston DN, Bodenner DL, Brett EM, Dralle H, Orloff LA, Pallota J, Snyder SK, Wong RJ \& Randolph GW. American Association of Clinical Endocrinologists and American College of Endocrinology disease state clinical review: postoperative hypoparathyroidism definitions and management. Endocrine Practice 201521 674-685. (https://doi.org/10.4158/EP14462.DSC)

22 Villarroya-Marquina I, Sancho J, Lorente-Poch L, Gallego-Otaegui L $\&$ Sitges-Serra A. Time to parathyroid function recovery in patients with protracted hypoparathyroidism after total thyroidectomy. European Journal of Endocrinology 2018178 103-111. (https://doi. org/10.1530/EJE-17-0589)

23 Villarroya-Marquina I, Lorente-Poch L, Sancho J \& Sitges-Serra A. Influence of gender and women's age on the prevalence of parathyroid failure after total thyroidectomy for multinodular goiter. Gland Surgery 20209 245-251. (https://doi.org/10.21037/gs.2020.02.01)

24 Rubin MR, Dempster DW, Zhou H, Shane E, Nickolas T, Sliney J Jr, Silverberg SJ \& Bilezikian JP. Dynamic and structural properties of the skeleton in hypoparathyroidism. Journal of Bone and Mineral Research 200823 2018-2024. (https://doi.org/10.1359/jbmr.080803)

25 Raue F, Pichl J, Dörr HG, Schnabel D, Heidemann P, Hammersen G, Jaursch-Hancke C, Santen R, Schöfl C, Wabitsch M, et al. Activating mutations in the calcium-sensing receptor: genetic and clinical spectrum in 25 patients with autosomal dominant hypocalcaemia - a German survey. Clinical Endocrinology 201175 760-765. (https://doi. org/10.1111/j.1365-2265.2011.04142.x)

26 David K, Moyson C, Vanderschueren D \& Decallonne B. Long-term complications in patients with chronic hypoparathyroidism: a crosssectional study. European Journal of Endocrinology 2019180 71-78. (https://doi.org/10.1530/EJE-18-0580)

27 Meena D, Prakash M, Gupta Y, Bhadada SK \& Khandelwal N. Carotid, aorta and renal arteries intima-media thickness in patients with sporadic idiopathic hypoparathyroidism. Indian Journal of Endocrinology and Metabolism 201519 262-266. (https://doi. org/10.4103/2230-8210.149320)

28 Agarwal P, Prakash M, Singhal M, Bhadada SK, Gupta Y \& Khandelwal N. To assess vascular calcification in the patients of hypoparathyroidism using multidetector computed tomography scan. Indian Journal of Endocrinology and Metabolism 201519 785-790. (https://doi.org/10.4103/2230-8210.167545)

29 Nandalur KR, Baskurt E, Hagspiel KD, Finch M, Phillips CD, Bollampally SR \& Kramer CM. Carotid artery calcification on CT may independently predict stroke risk. American Journal of Roentgenology 2006186 547-552. (https://doi.org/10.2214/AJR.04.1216)

30 Prabhakaran S, Singh R, Zhou X, Ramas R, Sacco RL \& Rundek T. Presence of calcified carotid plaque predicts vascular events: the Northern Manhattan Study. Atherosclerosis 2007195 e197-e201. (https://doi.org/10.1016/j.atherosclerosis.2007.03.044)

31 Kwee RM. Systematic review on the association between calcification in carotid plaques and clinical ischemic symptoms. Journal of Vascular Surgery 201051 1015-1025. (https://doi.org/10.1016/j.jvs.2009.08.072)

Received in final form 24 August 2020

Accepted 2 September 2020

Accepted Manuscript published online 3 September 2020

https://ec.bioscientifica.com https://doi.org/10.1530/EC-20-0387 (c) 2020 The authors Published by Bioscientifica Ltd
This work is licensed under a Creative Commons Attribution-NonCommercial-NoDerivatives 4.0 Internationab dicense.ifica . com at 04/26/2023 12:55:06PM 